\title{
Grazing of Nuclearia thermophila and Nuclearia delicatula (Nucleariidae, Opisthokonta) on the toxic cyanobacterium Planktothrix rubescens
}

\author{
Dirren, Sebastian ; Pitsch, Gianna ; Silva, Marisa O D ; Posch, Thomas
}

\begin{abstract}
During the last decades, the planktonic cyanobacterium Planktothrix rubescens became a dominant primary producer in many deep pre-alpine lakes. While altered physiochemical conditions due to lake warming seem to favour this cyanobacterial species, its dominance is partly attributed to factors conferring grazing resistance. The rigid structure of the cyanobacterial filaments and toxic secondary metabolites (e.g. microcystins) protect against diverse grazers. Nonetheless, species of the protistan genus Nuclearia (Nucleariidae, Opisthokonta) are able to overcome this grazing protection. Time lapse video documentation served as tool to record slow feeding processes of N. thermophila and N. delicatula. Three different feeding strategies could be distinguished: (i) Phagocytosis of small fragments, (ii) serial break-ups of cyanobacterial cells and (iii) bending and breaking of filaments. While observations revealed mechanical manipulation to be important for the efficient breakdown of P. rubescens filaments, the toxin microcystin had no pronounced negative effects on nucleariid cells. Growth experiments with N. thermophila/N. delicatula and different accompanying bacterial assemblages pointed to a pivotal role of distinct prokaryotic species for toxin degradation and for the growth success of the protists. Thus, the synergistic effect of nucleariids and specific bacteria favours an efficient degradation of P. rubescens along with its toxin.
\end{abstract}

DOI: https://doi.org/10.1016/j.ejop.2017.05.009

Posted at the Zurich Open Repository and Archive, University of Zurich

ZORA URL: https://doi.org/10.5167/uzh-144930

Journal Article

Accepted Version

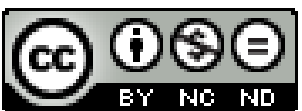

The following work is licensed under a Creative Commons: Attribution-NonCommercial-NoDerivatives 4.0 International (CC BY-NC-ND 4.0) License.

Originally published at:

Dirren, Sebastian; Pitsch, Gianna; Silva, Marisa O D; Posch, Thomas (2017). Grazing of Nuclearia thermophila and Nuclearia delicatula (Nucleariidae, Opisthokonta) on the toxic cyanobacterium Planktothrix rubescens. European Journal of Protistology, 60:87-101.

DOI: https://doi.org/10.1016/j.ejop.2017.05.009 


\title{
Grazing of Nuclearia thermophila and Nuclearia delicatula (Nucleariidae,
}

\section{Opisthokonta) on the toxic cyanobacterium Planktothrix rubescens}

\author{
Sebastian Dirren¹, Gianna Pitsch, Marisa O. D. Silva and Thomas Posch \\ Limnological Station, Department of Plant and Microbial Biology, University of Zurich, \\ Seestrasse 187, CH-8802 Kilchberg, Switzerland
}

Running Title: Feeding behaviour of Nuclearia spp.

Number of pages (incl. references \& figure legends): 34

Number of tables: 1

Number of coloured figures: 4 (Fig. 1, 3, 4, 5) and Graphical Abstract

Number of black and white figures: 4 (Fig. 2, 6, 7 and 8)

Number of videos: 2

Number of Supplementary Figures: 1

Intended as Research Article in 'European Journal of Protistology'

${ }^{1}$ Corresponding author:

Sebastian Dirren

Limnological Station, Department of Plant and Microbial Biology, University of Zurich

Seestrasse 187, CH-8802 Kilchberg, Switzerland

Phone: 0041446349214

Fax: 0041446349225

e-mail: s.dirren@limnol.uzh.ch 


\section{Abstract}

2 During the last decades, the planktonic cyanobacterium Planktothrix rubescens became a

3 dominant primary producer in many deep pre-alpine lakes. While altered physiochemical

4 conditions due to lake warming seem to favour this cyanobacterial species, its dominance is

5 partly attributed to factors conferring grazing resistance. The rigid structure of the

6 cyanobacterial filaments and toxic secondary metabolites (e.g. microcystins) protect against

7 diverse grazers. Nonetheless, species of the protistan genus Nuclearia (Nucleariidae,

8 Opisthokonta) are able to overcome this grazing protection. Time lapse video documentation

9 served as tool to record slow feeding processes of $N$. thermophila and $N$. delicatula. Three different feeding strategies could be distinguished: i) Phagocytosis of small fragments, ii) serial break-ups of cyanobacterial cells and iii) bending and breaking of filaments. While observations revealed mechanical manipulation to be important for the efficient breakdown of P. rubescens filaments, the toxin microcystin had no pronounced negative effects on nucleariid cells. Growth experiments with $N$. thermophila / N. delicatula and different accompanying bacterial assemblages pointed to a pivotal role of distinct prokaryotic species for toxin degradation and for the growth success of the protists. Thus, the synergistic effect of nucleariids and specific bacteria favours an efficient degradation of $P$. rubescens along with its toxin.

Keywords: cyanobacteria; grazing; microcystin; Nuclearia; Planktothrix; symbiont 


\section{Introduction}

In recent years, bloom forming cyanobacteria got in the focus of research as global warming and eutrophication have shown to increase their occurrence in diverse ecosystems (O'Neil et al., 2012). Since many of these in mass occurring cyanobacteria produce a cocktail of toxic secondary metabolites (e.g. microcystins, anatoxins and lipopolysaccharides), they are a concern in health and risk assessments (Carmichael, 2001). Beside this potential harmful aspect, they may play an important role as carbon source for heterotrophic organisms including bacteria, protozoa, metazoa and fungi (Sigee et al., 1999; Van Wichelen et al., 2016).

Planktothrix rubescens, a filamentous microcystin-producing cyanobacterium (Kurmayer et al., 2016), has become the dominant primary producer in the pelagial of many fresh water ecosystems, especially of deep pre-alpine lakes (Ernst et al., 2001; Jacquet et al., 2005; Posch et al., 2012).

Kurmayer and Jüttner (1999) showed that the zooplankton species have evolved strategies to co-exist with $P$. rubescens. According to the authors, the grazing resistance of the cyanobacterium was mainly attributed to chemical defence. In other studies the filamentous form was considered as an equivalent or even more important factor (Oberhaus et al., 2007).

Microcystins are the quantitatively most prominent bioactive secondary metabolites of P. rubescens (Blom et al., 2001). The inhibition of protein phosphatases PP1 and PP2A and the induction of oxidative stress are the main mechanisms for their toxicity in animal cells (Campos and Vasconcelos, 2010). Cytotoxic impacts are generally assumed to affect all eukaryotes including protists. While this is true for some protists like the amoeba Acanthamoeba castellanii, which was negatively affected (e.g. growth, physiological status and cytoskeleton) by ingested microcystin-producing cyanobacteria (Urrutia-Cordero et al., 2013), others like Naegleria sp. seemed to avoid or reject food particles containing this cyanotoxin (Liu et al., 2006). In contrast to these findings, certain protistan species feed 
actively on microcystin-containing cyanobacteria. No adverse effects of ingested toxic cyanobacteria was observed for some ciliates (Combes et al., 2013) and divers flagellates (Li et al., 2011; Mohamed and Al-Shehri, 2013; Nishibe et al., 2002; Ou et al., 2005; Wilken et al., 2010; Zhang et al., 2010). While an efficient biological degradation of microcystins was confirmed for many bacterial strains (Dziga et al., 2013), in eukaryotic organisms detoxification [e.g. glutathione S-transferase (Pflugmacher et al., 1998)] and mechanisms against oxidative stress [e.g. catalase (Ortiz-Rodríguez and Wiegand, 2010) / peroxidase (Jia et al., 2012)] play an important role to cope with the toxin. As far as we know, the only eukaryotes reported to degrade microcystins are the fungi Trichaptum abietinum (Jia et al., 2012), Trichoderma citrinoviride (Mohamed et al., 2014), the heterotrophic flagellate Diphylleia rotans (Mohamed and Al-Shehri, 2013), and the chrysophytes Ochromonas sp. (Wilken et al., 2010) and Poterioochromonas sp. (Ou et al., 2005; Zhang et al., 2010). The morphology of $P$. rubescens ( $\sim 5 \mu \mathrm{m}$ wide filaments up to $5 \mathrm{~mm}$ in length) is the other intrinsic factor conferring grazing protection. Many planktonic metazoans and protists are unable to ingest filaments which exceed their prey size range. Moreover, protistan grazers have difficulties handling the rigid trichomes formed by cyanobacterial cells. A specialized feeding apparatus and / or behaviour is needed to make filamentous cyanobacteria accessible as food source. Both attributes have been investigated in detail for Pseudomicrothorax dubius. This ciliate has a highly adapted cytopharyngeal basket to specifically ingest cyanobacterial filaments [(Hausmann and Peck, 1979); see video: https://av.tib.eu/media/9425?0]. Similar feeding behaviours were documented for other ciliates (Canter et al., 1990; Sudo et al., 1989) and flagellates (Brugerolle et al., 2002). In contrast, amoeboid protists have no specialized feeding apparatus to graze on filamentous cyanobacteria. Although exact descriptions of the feeding behaviour is often missing, among other amoebae (Dryden and Wright, 1987; Liu et al., 2006; Wright et al., 1981) representatives of the genus Nuclearia (Artari, 1889; Cann, 
1986; Cann and Page, 1979; Dirren and Posch, 2016; Dirren et al., 2014; Yamamoto and Suzuki, 1984) are able to use cyanobacterial filaments as sole food source.

An interesting aspect of nucleariid species is the frequent association with endo- and ectosymbiotic bacteria. In our previous studies we characterized $N$. thermophila and $N$. delicatula isolates together with their symbionts (Dirren and Posch, 2016; Dirren et al., 2014). While endosymbionts were detected intracellularly, the glycocalyx of $N$. thermophila strain $\mathrm{N}$ and $N$. delicatula strain G harboured the ectosymbionts Paucibacter toxinivorans and Inhella sp., respectively. The former one was originally described as a microcystin-degrading (variants: microcystin-LR, microcystin-YR and nodularin) bacterium (Rapala et al., 2005). After isolation of $N$. thermophila's ectosymbiont, its ability to degrade the microcystin variant [Asp $\left.{ }^{3}\right]$ microcystin-LR could be confirmed. Thus, it was hypothesized that these ectosymbiotic bacteria might degrade the microcystin contained in the food organism of its host (Dirren et al., 2014).

Here we report for the first time on the feeding behaviour of $N$. thermophila and $N$. delicatula ingesting toxic filamentous cyanobacteria, and combine these observations with microcystin measurements. Time lapse video documentation served as tool to record the slow feeding process. Quantifications of the cyanobacterium P. rubescens, its main toxin [D-Asp ${ }^{3}$, (E)-Dhb ${ }^{7}$ microcystin-RR, nucleariid cells and accompanying bacteria gave insights into the dynamics of this complex system. Further, we analysed the impact of accompanying bacteria on the lysis of cyanobacterial cells, microcystin degradation and growth success of nucleariids. Finally, we tested the hypothesis whether ectosymbionts are involved in the degradation of microcystin.

\section{Material and Methods}

\section{Strains and cultures}

Nuclearia thermophila strain N (GenBank accession number: HG530253) and Nuclearia delicatula strain G (GenBank accession number: LN875119) were isolated from Lake Zurich, 
Switzerland $\left(47^{\circ} 19^{\prime} 11.5^{\prime}{ }^{\prime} \mathrm{N}, 8^{\circ} 33^{\prime} 10.1^{\prime \prime} \mathrm{E}\right)$, in the years 2011 and 2012 , respectively. Single cells were picked and washed repeatedly in drops of sterile water to generate monoclonal xenic (plus bacteria) cultures. Isolates were kept in Tissue Culture Flask $25 \mathrm{~cm}^{2}$ (TPP) on autoclaved mineral water (Cristalp) under a $12 \mathrm{~h}$ light (irradiance of 5-15 $\mu \mathrm{mol} \mathrm{m}^{-2} \mathrm{~s}^{-1}$ ) / $12 \mathrm{~h}$ dark cycle. The food organism Planktothrix rubescens BC 9307 (Walsby et al., 1998), originally isolated from Lake Zurich, was grown axenically. Fortnightly new batch cultures were established by adding an aliquot $(\sim 1 \mathrm{ml})$ of the $P$. rubescens culture to $10 \mathrm{ml}$ mineral water and $200 \mu \mathrm{l}$ of an old Nuclearia culture (stationary phase) as inoculum. The ectosymbiotic bacterium of $N$. thermophila, Paucibacter toxinivorans strain SD41 (GenBank accession number: HG792253), was isolated in a previous study (Dirren et al., 2014) and cryopreserved in glycerol stocks $\left(-80^{\circ} \mathrm{C}\right)$. For the growth experiment, stocks were thawed and streaked onto R2 agar plates (Reasoner and Geldreich, 1985). Single colonies were then transferred to liquid R2 medium and grown until exponential growth phase. $N$. thermophila strain $\mathrm{N}$ and $N$. delicatula strain $\mathrm{G}$ have been deposited in the Culture Collection of Algae and Protozoa (CCAP) under the accession number CCAP 1552/5 and CCAP 1552/6, respectively.

\section{Growth experiment}

Growth experiments were performed in triplicates either with (i.e. $N$. thermophila / N. delicatula) or without nucleariids (i.e. bacterial cultures). Nine different set-ups (including controls) were prepared as shown in Table 1. While the exponentially growing Nuclearia cultures served directly as inoculum, cells of $P$. toxinivorans were harvested and washed twice (i.e. centrifugation at $7000 \mathrm{~g}$ for $15 \mathrm{~min}$ and exchange of medium with autoclaved mineral water) before adding to the respective set-ups. Unfortunately, Inhella sp. was not available as pure culture, thus no equivalent set-ups were prepared with these ectosymbiotic bacteria. Stock cultures of $P$. rubescens (i.e. one for set-ups 1-7 and another for set-up 8 and 9) were poured over a sterilised steel sieve (mesh size: $71 \mu \mathrm{m})$ and cyanobacterial filaments were collected on a second steel sieve (mesh size: $32 \mu \mathrm{m}$ ). Subsequently, cyanobacteria were 
washed with autoclaved mineral water $(\sim 1 \mathrm{~L})$ and re-suspended in $\sim 80 \mathrm{ml}$. Washed filaments were used directly as food source (stock: $P$. rubescens 'intact'). For set-ups 4 and 6 a part of the washed filaments was subjected to a freeze/thaw cycle in order to break up cyanobacterial cells (stock: P. rubescens 'broken').

Water from the benthic zone of Lake Zurich $\left(47^{\circ} 19^{\prime} 11.5^{\prime}{ }^{\prime} \mathrm{N}, 8^{\circ} 33^{\prime} 10.1^{\prime \prime} \mathrm{E}\right)$ was consecutively filtered twice over $0.8 \mu \mathrm{m}$ pore size polycarbonate filters. The filtrate containing bacteria from Lake Zurich (stock: 'Lake bacteria') was then used as medium in the respective set-ups. The following parameters were monitored for the different set-ups: cell counts of nucleariid cells, total bacterial abundances, biovolumes of $P$. rubescens and microcystin concentrations. Unfortunately, after $235 \mathrm{~h}$ a contaminant (flagellate) was observed in one parallel of set-up 2 (Table 1), therefore data from this parallel were excluded from analysis. All other parallels of each set-up were highly congruent: growth parameters, densities and concentrations are subsequently reported as averages with corresponding standard deviations.

\section{Quantification of cell abundances and biovolumes}

The growth of Nuclearia cells was followed by live counts in five drops of $20 \mu 1$ usually on a daily basis using an Axio Imager.M1 (Zeiss) microscope.

For the evaluation of bacterial abundances, $150 \mu 1$ of fixed samples (fin. conc. $2 \%$ formaldehyde) were stained with 4',6-diamidino-2-phenylindole (DAPI, fin. conc. $7 \mu \mathrm{g} \mathrm{ml}^{-1}$ for $2 \mathrm{~min})$ and filtered onto polycarbonate membranes $(0.2 \mu \mathrm{m}$ pore size $)$. Images of DAPI stained cells were acquired with an automated microscope (AxioImager Z1, Zeiss) controlled by the software AxioVision (Zeiss) and finally analysed as described previously (Zeder and Pernthaler, 2009; Zeder et al., 2009). Bacterial abundances were evaluated for the cultures ( $N$. thermophila, $N$. delicatula and P. toxinivorans) used for inoculation, the filtered lake water ('Lake bacteria') and for all parallels at different time points during the experiment. 
formaldehyde) were filtered (three replicates for each parallel) onto polycarbonate membranes

150

151

152

153

154

155

156

157

158

159

160

161

162 ( $5 \mu \mathrm{m}$ pore size). The total amount of filaments on filters had to be adjusted by using aliquots of different volumes $(15 \mu 1$ to $1500 \mu 1)$. Subsequently, the image analysis software PlanktothriQuant (Zeder et al., 2010) was used for the quantification. This evaluation was done for the stock culture of $P$. rubescens ( $P$. rubescens 'intact') and all parallels at two time points.

\section{Microcystin measurement}

Samples $(1 \mathrm{ml})$ for microcystin measurements were subjected to two freeze/thaw cycles, followed by 20 min ultrasound treatment (water bath sonication), and finally frozen until analyses were conducted. This was done in order to break up cells (i.e. bacteria, cyanobacteria and nucleariids) and release the intracellularly stored microcystins. Thus, subsequent measurements detected complete dissolved microcystin (i.e. in the medium + inside cells), except the potentially covalently bound molecules (e.g. to glutathione). After thawing, samples were mixed with methanol (fin. conc. $70 \%$ ), and filtered through a polyethersulphone syringe filter $0.2 \mu \mathrm{m}$ (IC Acrodisc, Pall Corporation). [D-Asp ${ }^{3},(E)$ $\left.\mathrm{Dhb}^{7}\right]$ microcystin-RR was analysed on a high performance liquid chromatography system (1260 Infinity series, Agilent Technologies) coupled with an API 5000 triple quadrupole mass spectrometer (AB Sciex). A C18 column Synergi Fusion-RP (50 x $2.00 \mathrm{~mm}, 4 \mu \mathrm{m}$ particle size, Phenomenex) was applied to separate microcystins. Two solvents were used: $1 \mathrm{mM}$ formic acid (Fluka) in water as solvent A and $100 \%$ methanol (J.T. Baker, Avantor) as solvent B. The following gradient was applied: Solvent B from $20 \%$ to $80 \%$ in 5 min; B 100 $\%$ for $2.5 \mathrm{~min}$ and B $20 \%$ for $2.5 \mathrm{~min}$. The flow rate was kept at $1 \mathrm{ml} \mathrm{min}^{-1}$. Nodularin $(5 \mu \mathrm{g}$ $\mathrm{L}^{-1}$ ) was chosen as the internal standard and injected in an external vial after 6 min of sample injection. Dilutions of $\left[\mathrm{D}-\mathrm{Asp}^{3},(E)\right.$-Dhb $\left.{ }^{7}\right]$ microcystin-RR were performed in order to prepare an accurate calibration curve in the range of $0.5-500 \mu \mathrm{g} \mathrm{L}^{-1}$. Both toxins used as standards, 
were extracted and purified (99\%) through HPLC and their specific molar absorption coefficient was used to prepare accurate standard solutions. The software Analyst (version 1.6.1, AB Sciex) served as tool for data acquisition and microcystin quantification was done using the MultiQuant software (version 3.0.1, AB Sciex).

\section{Microscopy: Photographic documentation, time lapse videos and drawings}

Micrographs of living specimens (usually on slides with cover slip) were taken with a Canon EOS1000D installed on an Axio Imager.M1 (Zeiss). Camera and microscope were controlled by the software AxioVision (Zeiss). The inverted microscope Axio Vert.A1 (Zeiss) was used for observations of cell motility and feeding behaviour (specimens were observed directly in culture flasks and microchambers). Both microscopes were equipped with optics for differential interference and phase contrast. Time lapse videos were acquired with an Axiocam 105 controlled by the dedicated module package available for the software Zen (Zeiss). VideoPad Video Editor (NCH Software Inc., USA) served as tool for processing and converting of time lapse videos. Cell motility and feeding behaviour were illustrated by drawings, which were based on live observation and micrographs. This artwork was generated with the software MediBang Paint Pro 8.1 (MediBang). Contrast, clarity and colouration of images were adjusted with Photoshop CS5 (Adobe Systems Inc., USA).

\section{Results}

\section{Morphology and locomotion of Nuclearia spp.}

The main morphological difference between $N$. thermophila (Fig. 1a-b) and $N$. delicatula (Fig. 1c) was their size. Individuals of $N$. thermophila were uninucleated and spherical cells had a body diameter of $16.4 \mu \mathrm{m}$ on average $(7.2-29 \mu \mathrm{m} ; \mathrm{n}=448)$. The multinucleate cells of $N$. delicatula were $26 \mu \mathrm{m}$ on average $(17.2-45.8 \mu \mathrm{m} ; \mathrm{n}=100)$. A glycocalyx surrounding the cell (a special feature of many Nuclearia spp.) was present in both investigated species. $N$. thermophila (cell diameter of $\sim 16 \mu \mathrm{m}$ ) was typically covered by an extracellular matrix with a thickness of $\sim 15 \mu \mathrm{m}$ (Fig. 2, 4 and 5). This structure is not visible but appears as translucent 
halo by light microscopy. Inside the glycocalyx only ectosymbionts (few micrometres distant from the cell membrane) were observed (Fig. 1), other bacteria or detritus are usually excluded. Our observations suggested a very dynamic nature of this structure. Fine filopodia elongated and retracted constantly through the translucent matrix apparently without facing resistance (Video 1). Additionally, big food particles could be moved through the glycocalyx without being hampered (Video 2). The plastic deformation during cell division and the formation of syncytia [see Figure S1 in Dirren et al. (2014)] further pointed to a highly manipulable character of the glycocalyx.

Despite the difference in size both nucleariid species displayed the same modes of locomotion. Nucleariid cells were observed in three different manifestations showing distinct types of cell motility. Individuals were either pelagic (Fig. 1a), attached with their filopodia to a surface (Fig. 2) or amoeboid forms on the ground of culture flasks (Fig. 3). Pelagic cells seemed to be capable of adjusting their vertical position, but currents in the waterbody mainly caused translocation in this state. After sedimentation, individuals used filopodia to attach to the ground followed by a horizontal movement of their cell bodies several micrometres above the ground ('walking': Fig. 2 and Video 1). Sliding on the outer borders of the extracellular structure was characteristic for this type of cell motility. The required force was produced by forward pointing filopodia, continuously attaching to the substrate and pulling the cell body into the respective direction. During this mode of locomotion highest speeds were reached $\left(1.14 \mu \mathrm{m} \mathrm{s}^{-1} ; \mathrm{n}=16\right)$. Occasionally, spherical individuals used filopodia to pull cell bodies towards the ground which led to the transition into the amoeboid form [as described by Surek and Melkonian (1980) in Figure 1a]. The subsequent movement was again dependent on forward pointing filopodia (Fig. 3 and Video 1). Polarized cells extending thick filopodia from a hyaline zone at their leading edge were characteristic for this type of cell motility. No lobopodia or plasma streams were observed during the amoeboid movement. While the glycocalyx was still present, the thickness between cell membrane and substrate reduced 
considerably to a few micrometres. In this way, exclusively the attaching and retracting filopodia allowed for the translocation as amoeboid cells on surfaces. All of the three types of cell motility were occasionally displayed by one and the same individual.

\section{Feeding behaviour of Nuclearia spp.}

The feeding behaviour of $N$. thermophila and $N$. delicatula were similar, but the larger cells of the latter species were able to ingest more food particles at once (Video 2). Individuals of all three manifestations actively fed on $P$. rubescens filaments. While pelagic cells rather passively encountered cyanobacterial fragments, surface attached cells 'searched' the ground for food particles (Video 2). When nucleariids approached P. rubescens, filopodia attached to cyanobacterial filaments. After attachment, individuals usually moved along filaments (by means of filopodia) until they reached a tip, where the feeding process was initiated.

Filopodia were then used to pull fragments towards the cell body. By this, the plasma membrane came in contact with the food and ingestion started. Subsequently, three ways of prey handling were observed. Filaments that were smaller than the nucleariid amoebae were taken up in one piece (Video 2). For filaments that were too large to be entirely ingested, two feeding behaviours were observed. First, spherical nucleariid cells engulfed only a little part of the filament, which was then moved constantly forwards and backwards (Fig. 4 and Video 2). Thereby the filament was sometimes ejected but usually contact was maintained by means of a big tube-like filopodium (Fig. 4a). During this mode of feeding, serial break-ups of cyanobacterial cells were observed (Fig. 4b). Particles which resulted from this break-up were then enclosed in food vacuoles (Fig. 4c) and finally transported inside the pseudopodium towards the cell body (Fig. 4d). Second, elongation of the nucleariid cell led to the engulfment of the filament along the entire amoeba (Fig. 5a). This was often followed by the bending of the fragment's outermost part (Fig. 5b). When filaments did not break, they often snapped back into their straight conformation and bending started again. After repetitive bending, small fragments eventually broke-off and were enclosed in food vacuoles (Fig. 5c). 
Occasionally, 'attacks' took place along cyanobacterial filaments and not at the tips. After engulfment of filaments in the middle, they were bended and finally broken (Video 2). This feeding behaviour was often observed for large $N$. delicatula cells.

\section{Growth dynamics of $N$. thermophila}

We studied effects of two distinct accompanying bacterial assemblages on the growth of $N$. thermophila (Fig. 6). A 'random' bacterial assemblage was generated as side effect of the method applied to isolate amoebae. Bacteria (entitled as 'Culture assemblage') were not selected for any special trait (e.g. efficiency, diversity or microcystin degradation) but rather for optimal growth of nucleariids. Thus the long term cultures of $N$. thermophila and $N$. delicatula probably did not result in 'natural' prokaryotic assemblages. For two set-ups an aliquot of this $N$. thermophila culture was used as inoculum (Table 1). While in set-up 1 sterile mineral water served as medium (only 'Culture assemblage'), lake water containing a natural bacterial assemblage was added to set-up 2 ('Culture assemblage' + 'Lake bacteria'). Growth dynamics (lag, log and stationary / death phase) of N. thermophila in the two set-ups were similar (Fig. 6a). While nucleariids together with the 'Culture assemblage' alone had a shorter lag phase (set-up 1: $98 \mathrm{~h}$; set-up 2: $122 \mathrm{~h}$ ), higher cell abundances (set-up 1: 3373 cells ml ${ }^{-1}$; set-up 2: 4035 cells $\mathrm{ml}^{-1}$ ) were reached when 'Lake bacteria' were present. Maximal growth rates $\mu_{\max }$ were $0.34 \mathrm{~d}^{-1}$ and $0.38 \mathrm{~d}^{-1}$ for set-up 1 and 2, respectively. Bacterial growth dynamics in the two set-ups were similar (Fig. 6b). Inoculation led immediately to an exponential increase of bacteria until a plateau was reached after $73 \mathrm{~h}$. The subsequent first stationary phase was shorter in set-up $1(\sim 47 \mathrm{~h})$ than in the set-up $2(\sim 92 \mathrm{~h})$. This was followed by a second exponential growth leading to maximal abundances (after 312 h) of $4.4 \times 10^{7}$ cells ml-1 in set-up 1 and $6.1 \times 10^{7}$ cells $\mathrm{ml}^{-1}$ in set-up 2 . Bacterial abundances remained low in the control. 

accompanying bacterial assemblages (Fig. 6c). In the control variant (set-up 7) we observed an increase of cyanobacterial biovolume.

In contrast to the very similar kinetics mentioned above, set-up 1 and 2 differed strikingly regarding the dynamics of microcystin concentrations (Fig. 6d). The same amount of $P$. rubescens 'intact' was added to these set-ups, resulting in a microcystin concentration of $116 \mu \mathrm{g} \mathrm{L}^{-1}$ at the beginning. In the control (set-up 7) variant, microcystin concentrations were stable for $165 \mathrm{~h}$ and then increased to $177 \mu \mathrm{g} \mathrm{L} \mathrm{L}^{-1}$ after $311 \mathrm{~h}$, which went in parallel with the increase of cyanobacterial biovolume. Cyanotoxin concentrations in set-up 1 increased slightly at the beginning. Thereafter, values fluctuated between $87 \mu \mathrm{g} \mathrm{L}^{-1}$ and $115 \mu \mathrm{g} \mathrm{L}^{-1}$. Therefore, there was virtually no net reduction of microcystins in the set-up with the 'Culture assemblage' alone. After a slight initial increase of microcystin concentrations in set-up 2,

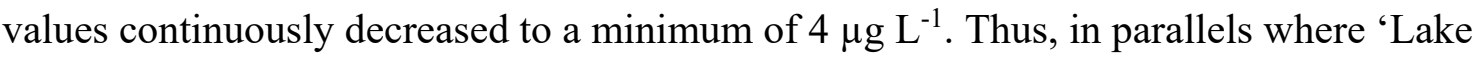
bacteria' were present, $96.6 \%$ of the added microcystin was removed after $311 \mathrm{~h}$.

\section{Growth dynamics of $N$. delicatula}

In contrast to the growth experiment with $N$. thermophila, $N$. delicatula was grown exclusively with its distinct 'Culture assemblage' (Fig. 7). short lag phase $(\sim 45 \mathrm{~h})$, which lasted only about half the time observed for $N$. thermophila, was followed by a rapid exponential growth $\left(\mu_{\max }=0.41 \mathrm{~d}^{-1}\right)$. Already after $123 \mathrm{~h}$ the maximal cell abundance of 1377 cells $\mathrm{ml}^{-1}$ was reached. $\left(2.8 \times 10^{7}\right.$ cells $\left.\mathrm{ml}^{-1}\right)$. 
While $P$. rubescens biovolume (Fig. 7c) was almost completely depleted already after $185 \mathrm{~h}$ when nucleariid cells were present, an increase in the control (set-up 9) was monitored. Essentially, dynamics of microcystin concentrations (Fig. 7d) were comparable in cultures of the two different nucleariid species growing with their distinct 'Culture assemblage' (Fig. 6d and 7d), but no fluctuations were monitored for the $N$. delicatula set-up. Since microcystin concentrations slightly increased, there was most likely no degradation of the cyanotoxin in the $N$. delicatula set-up. Increasing concentrations were also measured in the control (set-up 9), which was in line with the observed increase of cyanobacterial biovolume. In contrast to the former experiment the added $P$. rubescens filaments contained less microcystin per biovolume (set-up 1-7: $4.8 \mu \mathrm{g} \mathrm{mm}^{-3}$; set-up 8 and 9: $1.8 \mu \mathrm{g} \mathrm{mm}^{-3}$ ) and concentrations were in average $25 \%$ higher in the set-up 8 compared to the control (set-up 9). Planktothrix rubescens cultures were harvested in different growth phases (e.g. exponential vs stationary) when they were added to the respective set-ups (set-up 1-7 vs set-up 8 and 9).

Growth phase-dependent microcystin contents were also observed by Briand et al. (Briand et al., 2005). The difference in total concentration of the cyanotoxin between set-up 8 and the control (set-up 9) can be explained by the addition of microcystin contained in the $N$. delicatula culture used as inoculum.

\section{Bacterial growth on 'intact' and 'broken' Planktothrix rubescens filaments}

Growth curves of 'Lake bacteria' and $P$. toxinivorans with either $P$. rubescens 'intact' or $P$. rubescens 'broken' as substrate are depicted in Fig. 8a. Compared to set-up 3 with 'intact' $P$. rubescens, 'Lake bacteria' showed higher growth rates when 'broken' filaments (set-up 4) were offered. Highest bacterial abundances were reached in set-up 4 with $7.4 \times 10^{7}$ cells ml ${ }^{-1}$ after $216 \mathrm{~h}$, and in set-up 3 with $6.8 \times 10^{7}$ cells $\mathrm{ml}^{-1}$ after $312 \mathrm{~h}$. In set-ups 5 and $6 P$. toxinivorans did not grow at all independently whether P. rubescens was offered as 'intact' or 'broken’ biovolumes (Fig. 8a). 

seven set-ups (including control) at the beginning of experiments (Fig. $6 \mathrm{c}$ and $8 \mathrm{~b}$ ). Since $P$. rubescens 'broken' filaments underwent a freeze/thaw cycle, many cells were destroyed and thus their contents released as dissolved substances into the medium of the respective set-ups. Consequently, lower P. rubescens biovolumes were detected after $165 \mathrm{~h}$ (set-ups 4: $8.6 \mathrm{~mm}^{3}$ $\mathrm{L}^{-1}$ and set- up 6: $\left.11 \mathrm{~mm}^{3} \mathrm{~L}^{-1}\right)$. When 'intact' cyanobacteria were offered to 'Lake bacteria' (set-up 3), their biovolume slightly increased at the beginning but subsequently decreased to about half $\left(12.7 \mathrm{~mm}^{3} \mathrm{~L}^{-1}\right)$ of the initial amount. Similarly, P. rubescens biovolume which was still intact after freeze/thaw cycles further decreased in set-up 4. In the variants were $P$. toxinivorans was present, cyanobacterial biovolumes were not reduced due to bacterial activity. Planktothrix rubescens biovolume even increased in set-up 5 to a maximum of 35.8 $\mathrm{mm}^{3} \mathrm{~L}^{-1}$, which was higher than in the control $\left(31.9 \mathrm{~mm}^{3} \mathrm{~L}^{-1}\right)$. Microcystin concentrations in the different set-ups are depicted in Fig. 8c. When $P$. rubescens 'broken' was offered to 'Lake bacteria' (set-up 4), microcystins were reduced already after $73 \mathrm{~h}$ to about half $\left(61 \mu \mathrm{g} \mathrm{L}^{-1}\right)$ of the starting concentration $\left(116 \mu \mathrm{g} \mathrm{L}^{-1}\right)$, and to $20 \mu \mathrm{g} \mathrm{L}^{-1}$ at the end of the experiment. Thus, $83 \%$ of the offered microcystins were degraded. When $P$. rubescens 'intact' was added to 'Lake bacteria' (set-up 3), cyanotoxins were more slowly reduced, resulting in a net decrease of $55 \%$. In the set-ups with $P$. toxinivorans, micocystins were not degraded at all. We even noted increases of cyanotoxins in set-ups 5 and 6, which went in parallel with observations for the control.

\section{Discussion}

\section{Glycocalyx of Nuclearia spp.}

The glycocalyx is an extracellular structure composed of glycosylated proteins and lipids. A prominent and intensively studied example is the mucous layer of the gastrointestinal tract (Moran et al., 2011). There, glycoproteins and -lipids are anchored in the plasma membrane of epithelial cells forming the glycocalyx, which is covered by a second 
layer of secreted glycans. Similar extracellular structures have been described for rather basal animals like corals (Rosenberg et al., 2007) and cnidarians (Fraune et al., 2015). Here, the glycocalyx serves as an interface between host and bacterial microbiota and seems to be a conserved trait. Thus, one of the main functions of the extracellular barrier is the selection of probiotic bacterial species and the defence against pathogens (Bosch et al., 2015; Ouwerkerk et al., 2013). Probably, this is also the case for the basal opisthokonts in the family Nucleariidae. Most nucleariid species are surrounded by an extracellular structure composed of a mono- or a bilayer [see Table 1 in Yoshida et al. (2009)]. Some species are associated with specific bacterial ectosymbionts living in the glycocalyx [e.g. Inhella sp. associated with N. delicatula and P. toxinivorans associated with N. thermophila (Dirren and Posch, 2016)]. In relation to their small cell sizes, the dimensions of the extracellular layer are impressive. For $N$. thermophila the glycocalyx volume equals about two times the cell volume (Fig. 2, 4 and 5). Our observations during cell division, formation of syncytia, transformation into the amoeboid morphotype and food uptake revealed a highly dynamic and manipulable character of this structure. It is not at all an amorphous passive layer, but a highly structured matrix probably precisely controlled by cellular mechanisms. While the exclusion of bacterial invaders from the glycocalyx suggests high viscosity, big food particles can be moved through this structure seemingly without facing resistance. We propose two hypotheses for this apparent dual character of the extracellular matrix. (i) Filopodia are able to generate sufficient physical force to counteract the resistance caused by viscosity. (ii) Chemical interactions of excreted factors (e.g. proteases and lipases) with the glycoproteins and -lipids locally alter the properties of the matrix.

Considering the importance of the glycocalyx for many species including humans, nucleariid amoebae could serve as model organisms in future experiment to address such hypotheses. 


\section{Cell motility of Nuclearia spp.}

379 So far nucleariid species have been mainly isolated from benthic samples of lakes and ponds, and occasionally from the pelagial [see Table 1 in Dirren and Posch (2016)]. Amoeboid and spherical morphotypes are likely adaptions to different environmental conditions. While the attachment on surfaces allows the colonisation of substrates, moving on substrates most probably increases the food encounter rates in the benthos. Horizontal translocation as planktonic forms might be important for dispersal and enables nucleariids to contact food sources in the pelagic realm (e.g. P. rubescens). Planktothrix rubescens regulates its buoyancy via intracellular gas vesicles (Walsby et al., 2004). Through the ingestion of cyanobacteria, nucleariids could make use of these buoyant organelles to detach and rise in the water column. In analogy to e.g. spines in other planktonic organisms, filopodia of nucleariids could decrease sedimentation rates of amoebae. The variable length and quantity of pseudopodia could even allow for a fine tuning of buoyancy. characterised yet. The optical transparency of the extracellular matrix and the exclusive use of pseudopodia might give the impression of 'walking' cells (Fig. 2 and Video 1). In fact, spherical cells are sliding on the surface of their glycocalyx. Only filopodia seem to actively attach to the ground. Their retraction most likely generates the force to pull the cell body forwards. Except the transformation of filopodia, no rolling or deformation of the cell body occurs during this kind of motility.

The cell motility of amoeboid nucleariids has some unusual characteristics (Fig. 3 and Video 1). Models of amoeboid movement usually show the following sequence: First, lamellipodia and filopodia are formed at the leading edge and new adhesions under these protrusive structures are built. Then, the cell body with all its organelles is translocated forward. Finally, adhesions at the rear of the cell disassemble and the trailing edge retracts

403 [see Figure 1 in Mattila and Lappalainen (2008)]. In contrast to this classical model, no 
lamellipodia were observed for nucleariids. However, filopodia attach to the surface at the leading edge. Although the cell body is close to the surface, a thin layer of the glycocalyx still remains between the cell and the ground. Thus, amoeboid nucleariid cells are actively attached only by filopodia. No pronounced translocation of cell organelles and no retraction of the trailing edge were observed. Backwards pointing filopodia are simply detached and retracted. Thus, only the attachment, detachment and retraction of filopodia causes cell movements.

\section{Nucleariids grazing on Planktothrix rubescens}

(with a little help from their little friends)

To date, the range of accepted food particles has been determined for only one nucleariid species. Nineteen out of 45 offered algal species served as sole food source for Vampyrellidium perforans (Surek and Melkonian, 1980). Based on ultrastructure this species was later assigned to the genus Nuclearia by Patterson et al. (1987). Interestingly, the three offered cyanobacterial species (Anabaena cylindrica, Anabaena variabilis and Oscillatoria borneti) did not support amoebal growth. Since feeding experiments by Surek and Melkonian (1980) were conducted exclusively with axenic cultures, the presence of bacteria in our experiments could explain why $P$. rubescens was indeed a suitable food source for nucleariids.

Nuclearia thermophila and $N$. delicatula caused breakdowns of $P$. rubescens populations by the combination of physical forces (e.g. bending of filaments) and chemical digestion inside food vacuoles (e.g. acidification and enzymatic digestion). Additionally, our results suggest, that direct and indirect interactions with heterotrophic bacteria influence growth success of nucleariid cells.

Besides adverse physical conditions (i.e. abiotic factors) and cyanophages (Deng and Hayes, 2008), competition with bacteria and their excreted bio-active components could have a negative impact on P. rubescens . Partial cell lysis and fragmentation of cyanobacterial 
filaments caused by complete lysis of cells (i.e. within a filament) could facilitate a further breakdown by nucleariids. It was shown that bacteria are able to release cyanobacteria-lysing factors, e.g. amino acids, (antibiotic) peptides, enzymes, steroids, alkaloids, phenol derivatives, pigments and glycolipids [see Suppl. Table 2 from Van Wichelen et al. (2016)]. An accumulation of such bio-active components might be a prerequisite for successful feeding and growth of $N$. thermophila and $N$. delicatula. This hypothesis is supported by four observations. (i) 'Lake bacteria' were able to lyse about half of offered cyanobacterial biovolume, even when grown alone with $P$. rubescens (Fig. 8b). The reported ability of many heterotrophic bacteria to degrade cyanobacteria is in line with this result (Van Wichelen et al., 2016). (ii) Different feeding behaviours of nucleariid cells might point to different physiological status of their food, P. rubescens. Bending of filaments by nucleariids probably indicates that physical forces are required to attack 'healthy' cyanobacteria. When filaments were bent in newly inoculated cultures, they often did not break but snapped back and the process of bending started again. Insufficient bacterial degradation of cyanobacterial cells could explain these unsuccessful attacks. (iii) Time lapse videos showed that the breakage of P. rubescens filaments often coincides with an accumulation of bacteria (Video 2). Although the causative agent of cell lysis cannot be clearly attributed to bacteria, chemotactic behaviour of certain bacteria towards the cyanobacterium was evident. (iv) Growth dynamics of bacteria and nucleariid cells displayed a distinct succession in the respective set-ups (Fig. 6a-b and 7ab). While bacteria grew immediately after inoculation, nucleariids were still in a lag-phase. Probably, during this first bacterial growth phase cyanobacteria already started to degrade and break in smaller fragments (e.g. caused by excreted bio-active substances). This could explain the subsequent log-phase observed for nucleariid species. We documented even a more pronounced effect in a preliminary growth experiment, where the addition of the 'Culture assemblage' from $N$. thermophila to $N$. delicatula shortened the lag phase of the latter by about one third (Sup. Fig. 1). Consequently, the bacterial assemblage composition and 
probably excreted bio-active substances might be crucial for the growth success of nucleariids.

Regarding the degradation of cyanobacteria there is a great discrepancy between lab cultures and natural systems, e.g. the pelagial of deep pre-alpine lakes (Ernst et al., 2001; Jacquet et al., 2005; Posch et al., 2012). In contrast to the complete breakdown of $P$. rubescens populations in lab experiments with $N$. thermophila and $N$. delicatula, this cyanobacterial species seems to be protected from effective grazing in oligomesotrophic lakes. Probably, this phenomenon is attributed to insufficient concentrations of cyanobacterialysing substances. Low production, diffusion and dilution of these factors might be important processes conferring grazing protection to $P$. rubescens.

In addition to positive effects of bacterial assemblages on nucleariids, bacteria on the other hand most likely benefited from exponentially growing amoebae. The initial log-phase of bacteria was probably linked to dissolved carbon sources (e.g. from damaged $P$. rubescens cells), available already at the beginning of the experiment. Thus, their growth reached a plateau after the depletion of these accessible substrates. Subsequently, a second log-phase coincided with the exponential growth of nucleariid cells (Fig. 6a-b and 7a-b). This observation might be partly explained by substrates released during grazing (i.e. sloppy feeding) and by release (i.e. exocytosis) of indigestible components (Saba et al., 2011). Unfortunately, we don't know if this second bacterial log phase also reflected a taxonomic shift within bacterial assemblages.

In contrast to this positive effect on nucleariids, maximal cell abundances of 'Lake bacteria' were higher $\left(7.4 \times 10^{7}\right.$ bacteria $\left.\mathrm{ml}^{-1}\right)$ in set-ups with 'broken' $P$. rubescens, than in set-ups where $N$. thermophila was present $\left(6.1 \times 10^{7}\right.$ bacteria $\left.\mathrm{ml}^{-1}\right)$. This difference possibly mirrors the competition of amoebae with bacteria for the same resources. If exclusively dissolved substrates (i.e. sonicated $P$. rubescens cultures subsequently filtered through $0.2 \mu \mathrm{m}$ pore filter) were offered, no osmotrophic growth of $N$. thermophila could be observed (data 
not shown). This finding supports the assumption that from an evolutionary perspective, phagocytosis is a crucial trait of heterotrophic protists to compete and survive in a bacterial world. Although positive impacts on the two Nuclearia species by the accompanying bacterial assemblages prevailed in our experiments, growth of nucleariids could be also negatively affected by distinct bacterial strains. Antagonistic effects might be direct [e.g. spirillum-like bacteria feeding on the glycocalyx of $N$. thermophila see Figure 1I in Dirren et al. (2014)] or indirect (e.g. competition of certain bacteria with bacterial 'helper' strains). In sum, the interplay with accompanying bacteria is a critical factor for the growth success of $N$. thermophila and N. delicatula.

\section{Degradation of microcystin}

The fact that microcystin (i.e. $\left[\mathrm{D}-\mathrm{Asp}^{3},(E)-\mathrm{Dhb}^{7}\right]$ microcystin-RR) was reduced only in the set-ups with 'Lake bacteria' pointed to a bio-degradation caused by distinct bacterial species. In contrast, no net degradation was monitored for the two randomly generated 'Culture assemblages', leading to an accumulation of cyanotoxins. Thus, two conclusions can be drawn: (i) The microcystin variant of its food source was not degraded or covalently bound (e.g. via the glutathione S-transferase) by $N$. thermophila and by $N$. delicatula. (ii) Instead the cyanotoxin was released in the culture medium, where it became available for bacterial degraders.

Our experiments gave no indications for negative effects of [D-Asp ${ }^{3},(E)-$

$\left.\mathrm{Dhb}^{7}\right]$ microcystin-RR on nucleariid amoebae, which contradicts the general assumption that microcystins are harmful for all eukaryotes. This could be explained by two mechanisms. (i) The inhibition of protein phosphatases PP1 and PP2A by microcystins is one of the main causes for their toxicity (MacKintosh et al., 1990). Thus, structural variants of phosphatases might not be affected. This was shown, e.g. for the ciliate species Paramecium sp. which possess indeed different types of protein phosphatases (Plattner et al., 2009). The lack of the specific targets in combination with efficient export mechanisms would render the cyanotoxin 
harmless. (ii) Since microcystins are not cell membrane permeable, transporters are needed for their uptake. Members of the organic anion transporting polypeptide superfamily (Oatps) are known to mediate the transport of microcystins (Faltermann et al., 2016). The transport of microcystins is dependent on the specific Oatp and the microcystin variant (Fischer et al., 2005). Unfortunately, it is not known which transporters are expressed by nucleariid species. But, if nucleariids lack the appropriate transporters, microcystins would not be taken up. Digestion thus could occur as follows: Cyanobacteria are digested inside food vacuoles and their cell content, including microcystins, would be released. Subsequently, nutrients are actively absorbed by the nucleariids, but microcystins could still remain inside vacuoles. Exocytose would finally lead to the release of cyanotoxins into the culture medium. The ability of the ectosymbiont $P$. toxinivorans to degrade $\left[\mathrm{Asp}^{3}\right]$ microcystin-LR was previously shown (Dirren et al., 2014). Thus, a possible role in the degradation of cyanotoxins stored in the food source of $N$. thermophila seemed to be likely. In the current growth experiments no degradation of $\left[\mathrm{D}-\mathrm{Asp}^{3},(E)-\mathrm{Dhb}^{7}\right]$ microcystin-RR could be attributed to the ectosymbiotic bacteria of $N$. thermophila. This holds true for Inhella sp. the ectosymbiont of $N$. delicatula, which also did not degrade the microcystin variant expressed by the offered cyanobacterium. Paucibacter toxinivorans was harboured inside the glycocalyx of $N$. thermophila in set-up 1 and 2 and Inhella sp. was associated with $N$. delicatula in set-up 8. However, only if 'Lake bacteria' were present (set-up 2), a degradation of cyanotoxins was monitored. Microcystin was not degraded when P. toxinivorans was confronted with 'intact' or 'broken' P. rubescens (set-ups 5 and 6). This findings suggest that under the applied experimental conditions both ectosymbionts are not able to degrade the [D-Asp ${ }^{3},(E)$ $\mathrm{Dhb}^{7}$ ]microcystin-RR stored in the food source of their hosts. 
533 Degradation dynamics of $P$. rubescens and its toxin differed remarkably in the various set-

534 ups. Cyanobacterial filaments were almost completely eliminated exclusively if nucleariid amoebae were present. Our results suggested that the combination of bacterial lysis together with the feeding activity of nucleariids caused an efficient breakdown of $P$. rubescens biovolume. Nuclearia thermophila and $N$. delicatula did not degrade the microcystin variant stored in their cyanobacterial food. Instead distinct accompanying bacterial species were responsible for the toxin removal. Taken together, in addition to the presence of nucleariid cells two requirements have to be fulfilled for an efficient degradation of $P$. rubescens along with its toxin: Cyanobacterial filaments have to be partially degraded (e.g. unfavourable physiological conditions, cyanobacteria-lysing factors and / or cyanophages) and members of

543 the bacterial assemblage must be able to degrade released microcystins.

544 The role of the ectosymbiont $P$. toxinivorans as microcystin-RR degrader could not be 545 confirmed in the investigated system. Since nucleariid species have a broad prey range, the 546 possible involvement of their ectosymbionts in the degradation of different microcystin 547 variants (e.g. microcystin-LR) stored in alternative food sources (e.g. Microcystis sp.) should 548 be addressed in future experiments. However, the close proximity of these ectosymbiontic 549 bacteria to the host's membrane suggests an exchange of metabolites. Future experiments 550 should address metabolic capabilities of ectosymbionts to pinpoint the role of this associated 551 bacteria for nucleariid species. 
$552 \quad$ Funding

553 This study was financed by the Swiss National Fund (SNF 31003A_159842).

554 Acknowledgements

555 We thank Jakob Pernthaler (University of Zurich) for fruitful discussions.

556 The authors declared no conflicts of interest.

557 Appendix A. Supplementary data

558 Supplementary data associated with this article can be found, in the online version, at 559 https://doi.org/10.1016/i.ejop.2017.05.009 
Artari, A., 1889. Morphologische und biologische Studien über Nuclearia delicatula, Cienk. Zool. Anz. $12,408-416$.

Blom, J.F., Robinson, J.A., Jüttner, F., 2001. High grazer toxicity of [D-Asp ${ }^{3}$,(E)-Dhb $\left.{ }^{7}\right]$ microcystin-RR of Planktothrix rubescens as compared to different microcystins. Toxicon 39, 1923-1932.

Bosch, T.C., Grasis, J., Lachnit, T., 2015. Microbial ecology in Hydra: Why viruses matter. J. Microbiol. 53, 193-200.

Briand, J.-F., Jacquet, S., Flinois, C., Avois-Jacquet, C., Maisonnette, C., Leberre, B., Humbert, J.-F., 2005. Variations in the microcystin production of Planktothrix rubescens (cyanobacteria) assessed from a four-year survey of Lac du Bourget (France) and from laboratory experiments. Microb. Ecol. 50, 418-428.

Brugerolle, G., Bricheux, G., Philippe, H., Coffe, G., 2002. Collodictyon triciliatum and Diphylleia rotans (= Aulacomonas submarina) form a new family of flagellates (Collodictyonidae) with tubular mitochondrial cristae that is phylogenetically distant from other flagellate groups. Protist 153, 59-70.

Campos, A., Vasconcelos, V., 2010. Molecular mechanisms of microcystin toxicity in animal cells. Int. J. Mol. Sci. 11, 268-287.

Cann, J.P., 1986. The feeding behavior and structure of Nuclearia delicatula (Filosea: Aconchulinida). J. Protozool. 33, 392-396.

Cann, J.P., Page, F.C., 1979. Nucleosphaerium tuckeri nov. gen. nov. sp.- A new freshwater filose amoeba without motile form in a new family Nucleariidae (Filosea: Aconchulinida) feeding by ingestion only. Arch. Protistenk. 122, 226-240.

Canter, H.M., Heaney, S.I., Lund, J.W.G., 1990. The ecological significance of grazing on planktonic populations of cyanobacteria by the ciliate Nassula. New Phytol. 114, 247-263.

Carmichael, W.W., 2001. Health effects of toxin-producing cyanobacteria: "The CyanoHABs". Hum. Ecol. Risk. Assess. 7, 1393-1407.

Combes, A., Dellinger, M., Cadel-six, S., Amand, S., Comte, K., 2013. Ciliate Nassula sp. grazing on a microcystin-producing cyanobacterium (Planktothrix agardhii): impact on cell growth and in the microcystin fractions. Aquat. Toxicol. 126, 435-441.

Deng, L.I., Hayes, P.K., 2008. Evidence for cyanophages active against bloom-forming freshwater cyanobacteria. Freshwater Biol. 53, 1240-1252.

Dirren, S., Posch, T., 2016. Promiscuous and specific bacterial symbiont acquisition in the amoeboid genus Nuclearia (Opisthokonta). FEMS Microbiol. Ecol. 92.

Dirren, S., Salcher, M.M., Blom, J.F., Schweikert, M., Posch, T., 2014. Ménage-à-trois: The amoeba Nuclearia sp. from Lake Zurich with its ecto- and endosymbiotic bacteria. Protist 165, 745-758.

Dryden, R.C., Wright, S.J.L., 1987. Predation of cyanobacteria by protozoa. Can. J. Microbiol. 33, 471482. 
Dziga, D., Wasylewski, M., Wladyka, B., Nybom, S., Meriluoto, J., 2013. Microbial degradation of microcystins. Chem. Res. Toxicol. 26, 841-852.

Ernst, B., Hitzfeld, B., Dietrich, D., 2001. Presence of Planktothrix sp. and cyanobacterial toxins in Lake Ammersee, Germany and their impact on whitefish (Coregonus lavaretus L.). Environ. Toxicol. 16, 483-488.

Faltermann, S., Prétôt, R., Pernthaler, J., Fent, K., 2016. Comparative effects of nodularin and microcystin-LR in zebrafish: 1 . Uptake by organic anion transporting polypeptide Oatp1d1 (SIco1d1). Aquat. Toxicol. 171, 69-76.

Fischer, W.J., Altheimer, S., Cattori, V., Meier, P.J., Dietrich, D.R., Hagenbuch, B., 2005. Organic anion transporting polypeptides expressed in liver and brain mediate uptake of microcystin. Toxicol. Appl. Pharm. 203, 257-263.

Fraune, S., Anton-Erxleben, F., Augustin, R., Franzenburg, S., Knop, M., Schroder, K., Willoweit-Ohl, D., Bosch, T.C.G., 2015. Bacteria-bacteria interactions within the microbiota of the ancestral metazoan Hydra contribute to fungal resistance. ISME J. 9, 1543-1556.

Hausmann, K., Peck, R.K., 1979. The mode of function of the cytopharyngeal basket of the ciliate Pseudomicrothorax dubius. Differentiation 14, 147-158.

Jacquet, S., Briand, J.-F., Leboulanger, C., Avois-Jacquet, C., Oberhaus, L., Tassin, B., Vinçon-Leite, B., Paolini, G., Druart, J.-C., Anneville, O., Humbert, J.-F., 2005. The proliferation of the toxic cyanobacterium Planktothrix rubescens following restoration of the largest natural French lake (Lac du Bourget). Harmful Algae 4, 651-672.

Jia, Y., Du, J., Song, F., Zhao, G., Tian, X., 2012. A fungus capable of degrading microcystin-LR in the algal culture of Microcystis aeruginosa PCC7806. Appl. Biochem. Biotech. 166, 987-996.

Kurmayer, R., Deng, L., Entfellner, E., 2016. Role of toxic and bioactive secondary metabolites in colonization and bloom formation by filamentous cyanobacteria Planktothrix. Harmful Algae 54, 6986.

Kurmayer, R., Jüttner, F., 1999. Strategies for the co-existence of zooplankton with the toxic cyanobacterium Planktothrix rubescens in Lake Zurich. J. Plankton Res. 21, 659-683.

Li, J., Shimizu, K., Zhou, Y., Utsumi, M., Sakharkar, M.K., Zhang, Z., Sun, H., Sugiura, N., 2011. Biodegradation of microcystins by bacterial communities co-existing with the flagellate Monas guttula and concurrent succession of community structures. J. Water Supply Res. T. 60, 352-363.

Liu, X.Y., Shi, M., Liao, Y.H., Gao, Y., Zhang, Z.K., Wen, D.H., Wu, W.Z., An, C.C., 2006. Feeding characteristics of an amoeba (Lobosea : Naegleria) grazing upon cyanobacteria: Food selection, ingestion and digestion progress. Microb. Ecol. 51, 315-325.

MacKintosh, C., Beattie, K.A., Klumpp, S., Cohen, P., Codd, G.A., 1990. Cyanobacterial microcystin-LR is a potent and specific inhibitor of protein phosphatases 1 and $2 A$ from both mammals and higher plants. FEBS Lett. 264, 187-192.

Mattila, P.K., Lappalainen, P., 2008. Filopodia: molecular architecture and cellular functions. Nat. Rev. Mol. Cell Biol. 9, 446-454. 
Mohamed, Z.A., Al-Shehri, A.M., 2013. Grazing on Microcystis aeruginosa and degradation of microcystins by the heterotrophic flagellate Diphylleia rotans. Ecotox. Environ. Safe. 96, 48-52.

Mohamed, Z.A., Hashem, M., Alamri, S.A., 2014. Growth inhibition of the cyanobacterium Microcystis aeruginosa and degradation of its microcystin toxins by the fungus Trichoderma citrinoviride. Toxicon 86, 51-58.

Moran, A.P., Gupta, A., Joshi, L., 2011. Sweet-talk: role of host glycosylation in bacterial pathogenesis of the gastrointestinal tract. Gut 60, 1412-1425.

Nishibe, Y., Kawabata, Z., Nakano, S., 2002. Grazing on Microcystis aeruginosa by the heterotrophic flagellate Collodictyon triciliatum in a hypertrophic pond. Aquat. Microb. Ecol. 29, 173-179.

O'Neil, J.M., Davis, T.W., Burford, M.A., Gobler, C.J., 2012. The rise of harmful cyanobacteria blooms: The potential roles of eutrophication and climate change. Harmful Algae 14, 313-334.

Oberhaus, L., Gélinas, M., Pinel-Alloul, B., Ghadouani, A., Humbert, J.-F., 2007. Grazing of two toxic Planktothrix species by Daphnia pulicaria: potential for bloom control and transfer of microcystins. J. Plankton Res. 29, 827-838.

Ortiz-Rodríguez, R., Wiegand, C., 2010. Age related acute effects of microcystin-LR on Daphnia magna biotransformation and oxidative stress. Toxicon 56, 1342-1349.

Ou, D., Song, L., Gan, N., Chen, W., 2005. Effects of microcystins on and toxin degradation by Poterioochromonas sp. Environ. Toxicol. 20, 373-380.

Ouwerkerk, J.P., de Vos, W.M., Belzer, C., 2013. Glycobiome: Bacteria and mucus at the epithelial interface. Best. Pract. Res. Cl. Ga. 27, 25-38.

Patterson, D.J., Surek, B., Melkonian, M., 1987. The ultrastructure of Vampyrellidium perforans Surek \& Melkonian and its taxonomic position among the naked filose amoebae. J. Protozool. 34, 63-67.

Pflugmacher, S., Wiegand, C., Oberemm, A., Beattie, K.A., Krause, E., Codd, G.A., Steinberg, C.E.W., 1998. Identification of an enzymatically formed glutathione conjugate of the cyanobacterial hepatotoxin microcystin-LR: the first step of detoxication. Biochim. Biophys. Acta 1425, 527-533.

Plattner, H., Sehring, I.M., Schilde, C., Ladenburger, E.M., 2009. Pharmacology of ciliated protozoa drung (in)sensitivity and experimental drug (ab)use, in: Jeon, K.W. (Ed.), Int. Rev. Cel. Mol. Bio., pp. 163-218.

Posch, T., Koster, O., Salcher, M.M., Pernthaler, J., 2012. Harmful filamentous cyanobacteria favoured by reduced water turnover with lake warming. Nat. Clim. Change 2, 809-813.

Rapala, J., Berg, K.A., Lyra, C., Niemi, R.M., Manz, W., Suomalainen, S., Paulin, L., Lahti, K., 2005. Paucibacter toxinivorans gen. nov., sp nov., a bacterium that degrades cyclic cyanobacterial hepatotoxins microcystins and nodularin. Int. J. Syst. Evol. Microbiol. 55, 1563-1568.

Reasoner, D.J., Geldreich, E.E., 1985. A new medium for the enumeration and subculture of bacteria from potable water. Appl. Environ. Microbiol. 49, 1-7.

Rosenberg, E., Koren, O., Reshef, L., Efrony, R., Zilber-Rosenberg, I., 2007. The role of microorganisms in coral health, disease and evolution. Nat. Rev. Micro. 5, 355-362. 
Saba, G.K., Steinberg, D.K., Bronk, D.A., 2011. The relative importance of sloppy feeding, excretion, and fecal pellet leaching in the release of dissolved carbon and nitrogen by Acartia tonsa copepods. J. Exp. Mar. Biol. Ecol. 404, 47-56.

Sigee, D.C., Glenn, R., Andrews, M.J., Bellinger, E.G., Butler, R.D., Epton, H.A.S., Hendry, R.D., 1999. Biological control of cyanobacteria: principles and possibilities. Hydrobiologia 395, 161-172.

Sudo, R., Inamori, Y., Kuniyasu, Y., Ouchiyama, T., 1989. Predation and deodorization of musty odorproducing filamentous algae by the protozoa Trithigmostoma cucullulus. Water Sci. Technol. 21, 1743-1746.

Surek, B., Melkonian, M., 1980. The filose amoeba Vampyrellidium perforans nov. sp. (Vampyrellidae, Aconchulinida): Axenic culture, feeding behaviour and host range specifity. Arch. Protistenk. 123, 166-191.

Urrutia-Cordero, P., Agha, R., Cirés, S., Lezcano, M.Á., Sánchez-Contreras, M., Waara, K.-O., Utkilen, H., Quesada, A., 2013. Effects of harmful cyanobacteria on the freshwater pathogenic free-living amoeba Acanthamoeba castellanii. Aquat. Toxicol. 130-131, 9-17.

Van Wichelen, J., Vanormelingen, P., Codd, G.A., Vyverman, W., 2016. The common bloom-forming cyanobacterium Microcystis is prone to a wide array of microbial antagonists. Harmful Algae 55, 97111.

Walsby, A.E., Avery, A., Schanz, F., 1998. The critical pressures of gas vesicles in Planktorhrix rubescens in relation tothe depth of winter mixing in Lake Zurich, Switzerland. J. Plankton Res. 20, 1357-1375.

Walsby, A.E., Ng, G., Dunn, C., Davis, P.A., 2004. Comparison of the depth where Planktothrix rubescens stratifies and the depth where the daily insolation supports its neutral buoyancy. New Phytol. 162, 133-145.

Wilken, S., Wiezer, S., Huisman, J., Van Donk, E., 2010. Microcystins do not provide anti-herbivore defence against mixotrophic flagellates. Aquat. Microb. Ecol. 59, 207-216.

Wright, S.J.L., Redhead, K., Maudsley, H., 1981. Acanthamoeba castellanii. a predator of cyanobacteria. J. Gen. Microbiol. 125, 293-300.

Yamamoto, Y., Suzuki, K., 1984. Light and electron microscope observations and prey specificities of an algophorous amoeba from Japanese freshwater. J. Gen. Appl. Micrbiol. 30, 411-417.

Yoshida, M., Nakayama, T., Inouye, I., 2009. Nuclearia thermophila sp. nov. (Nucleariidae), a new nucleariid species isolated from Yunoko Lake in Nikko (Japan). Europ. J. Protistol. 45, 147-155.

Zeder, M., Pernthaler, J., 2009. Multispot live-image autofocusing for high-throughput microscopy of fluorescently stained bacteria. Cytom. Part A 75A, 781-788.

Zeder, M., Peter, S., Shabarova, T., Pernthaler, J., 2009. A small population of planktonic Flavobacteria with disproportionally high growth during the spring phytoplankton bloom in a prealpine lake. Environ. Microbiol. 11, 2676-2686.

Zeder, M., Van den Wyngaert, S., Köster, O., Felder, K.M., Pernthaler, J., 2010. Automated quantification and sizing of unbranched filamentous cyanobacteria by model-based object-oriented image analysis. Appl. Environ. Microbiol. 76, 1615-1622. 
Zhang, X., Hu, H., Men, Y., Christoffersen, K.S., 2010. The effect of Poterioochromonas abundance on production of intra- and extracellular microcystin-LR concentration. Hydrobiologia 652, 237-246.

\section{Figure 1}

Light micrographs of $N$. thermophila (a and b) and $N$. delicatula (c). (a) Spherical nucleariid cell surrounded by bacterial ectosymbionts ( $P$. toxinivorans) feeding on the filamentous cyanobacterium $P$. rubescens. (b) Amoeboid cell with associated $P$. toxinivorans symbionts. Nucleus with its nucleolus and food vacuoles containing remnants of the food organism are visible inside the cell body. (c) Amoeboid nucleariid cell with ectosymbiotic bacteria (Inhella sp.) displaying four nuclei and several food vacuoles. Differential interference contrast images. Scale bars $20 \mu \mathrm{m}$.

\section{Figure 2}

Drawings of $N$. thermophila illustrating the cell motility referred to as 'walking'. Forward pointing filopodia are numbered. Note the shaded glycocalyx containing the ectosymbiont $P$. toxinivorans located few micrometres distant from the cell membrane. The nucleariid cell containing nucleus / nucleolus and food vacuoles is sliding on the outer border of the extracellular matrix. Swellings of filopodia are characteristic for points of attachment. (a-c) Consecutive snap shots of the nucleariid cell moving on a surface. Filopodia elongate (e.g. no. 3 in a), attach to the surface (e.g. no. 3 in b) and are retracted (e.g. no. 3 in c). This process leads to the translocation of the cell.

\section{Figure 3}

Light micrographs of $N$. delicatula moving as amoeboid cell on a surface. The ectosymbiotic bacteria (Inhella sp.) are located around the multinucleated species. Forward pointing filopodia of the polarized cell are numbered. Points of attachment are indicated by arrow heads. (a-c) Consecutive snap shots of a cell displaying the amoeboid cell motility. Filopodia elongate (e.g. no. 4 in a), attach to the surface (e.g. no. 4 in b) and are retracted (e.g. no. 4 in c). Phase contrast images. Scale bars $50 \mu \mathrm{m}$. 


\section{Figure 4}

Feeding of $N$. thermophila by serial break-ups of cyanobacterial cells (P. rubescens: red). (a)

Overview of a nucleariid cell with its glycocalyx containing the ectosymbiont $P$. toxinivorans. Nucleus / nucleolus and food vacuoles with remnants of cyanobacterial filaments are visible inside the cell. While thin filopodia are radiating evenly distributed from the cell body, a thick tube-like filopodium engulfs a filament of $P$. rubescens. The break-up of a single cyanobacterial cell (magnification of the square in a) is shown in (b-d). (b) The cell at the tip of the cyanobacterial filament starts degrading. (c) Particles of the partly degraded cell are enclosed in a small food vacuole. (d) The food vacuole is transported through the filopodium towards the cell body.

\section{Figure 5}

Feeding of $N$. thermophila by bending and breaking of a cyanobacterial filament $(P$. rubescens: red). The glycocalyx containing the ectosymbiont $P$. toxinivorans covers the nucleariid cell. Filopodia are radiating from the cell membrane. Nucleus / nucleolus and two food vacuoles are visible inside the cell. (a) Elongation enables the engulfment (i.e. formation of a food vacuole) of the cyanobacterial filament over the entire body length. (b) Mechanical force is generated by the nucleariid cell causing bending of the filament. (c) Bending finally results in the breakage of the filament. The small fragment originating from the breakage is eventually enclosed in a food vacuole.

\section{Figure 6}

Growth experiment of $N$. thermophila (associated with the ectosymbiont $P$. toxinivorans) feeding on the cyanobacterium $P$. rubescens. Nucleariid cells were grown with two different accompanying bacterial assemblages: In set-up 1 with the 'Culture assemblage' and in set-up 2 with the 'Culture assemblage' + 'Lake bacteria' (see text and Table 1). Cultures of the food organism P. rubescens alone served as control (set-up 7). Averages of parallels (set-up 1: 3; set-up 2: 2) with corresponding standard deviations are shown (except values for to, which 
were calculated from measurements of stock cultures). (a) Growth curves of the nucleariid cells displayed similar dynamics in the two set-ups. (b) Bacterial abundances in set-up 1 and 2 were comparable over the entire experiment. (c) Biovolume of $P$. rubescens (Planktothrix Biovol.) at three time points during the growth experiment. The cyanobacteria in the two setups were almost completely depleted after $312 \mathrm{~h}$. In contrast cyanobacterial biovolume increased in the control. (d) $\left[\mathrm{D}-\mathrm{Asp}^{3},(E)-\mathrm{Dhb}^{7}\right]$ microcystin-RR concentrations measured during the growth experiment. Dynamics differed strikingly between the two set-ups. While no net reduction was observed for set-up 1 , the cyanotoxin was almost completely degraded in set-up 2 after $311 \mathrm{~h}$. Increasing concentrations in the control were in line with the increase in biovolume of $P$. rubescens.

\section{Figure 7}

Growth experiment of $N$. delicatula (associated with the ectosymbiont Inhella sp.) feeding on the cyanobacterium $P$. rubescens. As control the food organism was grown alone (set-up 9). Averages of three parallels with corresponding standard deviations are shown (except values for to, which were calculated from measurements of stock cultures). (a) A typical growth curve of $N$. delicatula with lag, log and stationary / death phase was recorded. (b) Bacterial abundance showed twice a prominent increase, the first in the beginning and the second after 123 h. No bacteria were detected in the control. (c) Biovolume of P. rubescens (Planktothrix Biovol.) was measured at the beginning (stock culture), after the exponential growth of nucleariid cells and at the end of the experiment. While the food organism was almost completely depleted in set-up 8 after 185 h, an increase was monitored for the control. (d) [D$\left.\mathrm{Asp}^{3},(E)-\mathrm{Dhb}^{7}\right]$ microcystin-RR concentrations at different time points during the experiment. Concentrations at $t_{0}$ were measured in one of the parallels, apart from that averages with standard deviations are shown. No degradation of the cyanotoxin was detected. Instead concentrations increased in set-up 8 and in the control. 


\section{Figure 8}

848 Growth experiment of 'Lake bacteria' (set-up 3 and 4) and the ectosymbiont $P$. toxinivorans

849 (P. tox.: set-up 5 and 6). P. rubescens (P. rub) was offered as substrate (see text and Table 1).

850 The cyanobacterial cells were either added untreated ( $P$. rub 'intact': set-up 3 and 5) or after a

851 freeze/thaw cycle ( $P$. rub 'broken': set-up 4 and 6). Cultures of the food organism $P$.

852 rubescens alone served as control. Averages of three parallels with corresponding standard

853 deviations are shown (except values for $t_{0}$, which were calculated from measurements of stock

854 cultures). (a) Bacterial abundances in the different set-ups. Moderate and fast growth was

855 observed in set-up 3 and 4, respectively. No proliferation was monitored in set-up 5 and 6.

856 Bacterial counts in the control were low. (b) Biovolume of P. rubescens (Planktothrix

857 Biovol.) at three time points during the growth experiment. Cross indicate that biovolume was

858 measured before cells were subjected to a freeze/thaw cycle. While bacterial lysis partly

859 depleted $P$. rubescens in set-up 3 and 4, no degradation was observed for the set-ups with $P$.

860 toxinivorans. (c) $\left[\mathrm{D}-\mathrm{Asp}^{3},(E)-\mathrm{Dhb}^{7}\right]$ microcystin-RR concentrations measured during the

861 growth experiment. Microcystin was partly degraded in the set-ups with 'Lake bacteria'. No

862 degradation of the cyanotoxin was observed in the set-ups with P. toxinivorans. 

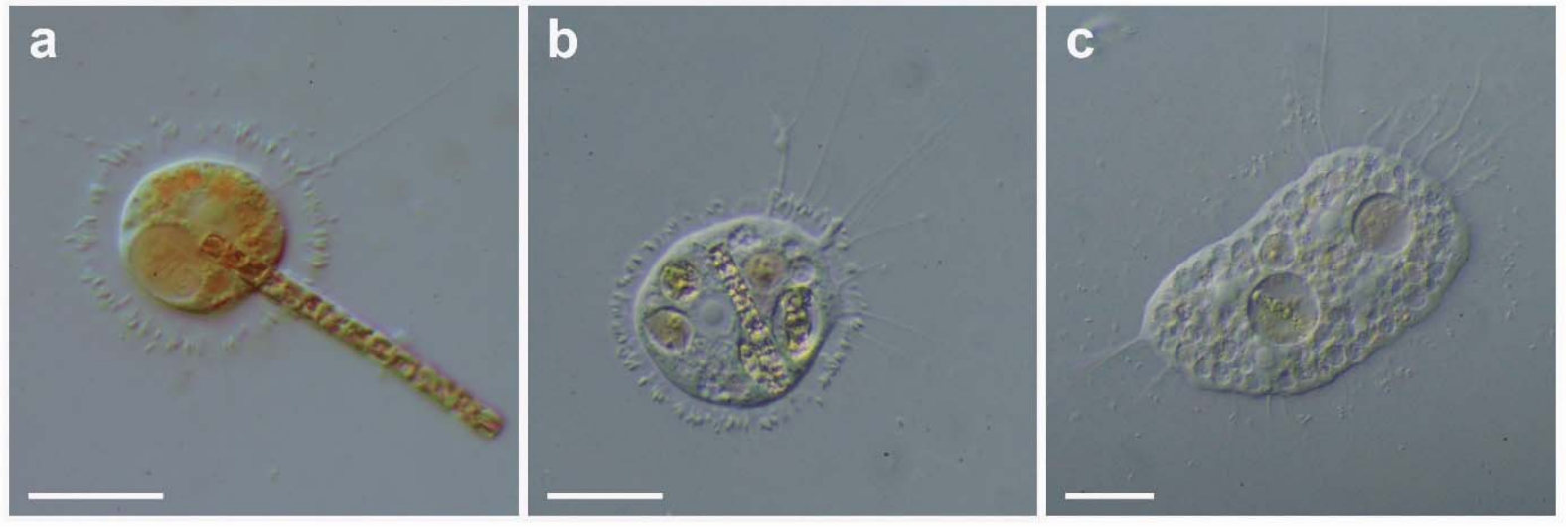

Figure 1 

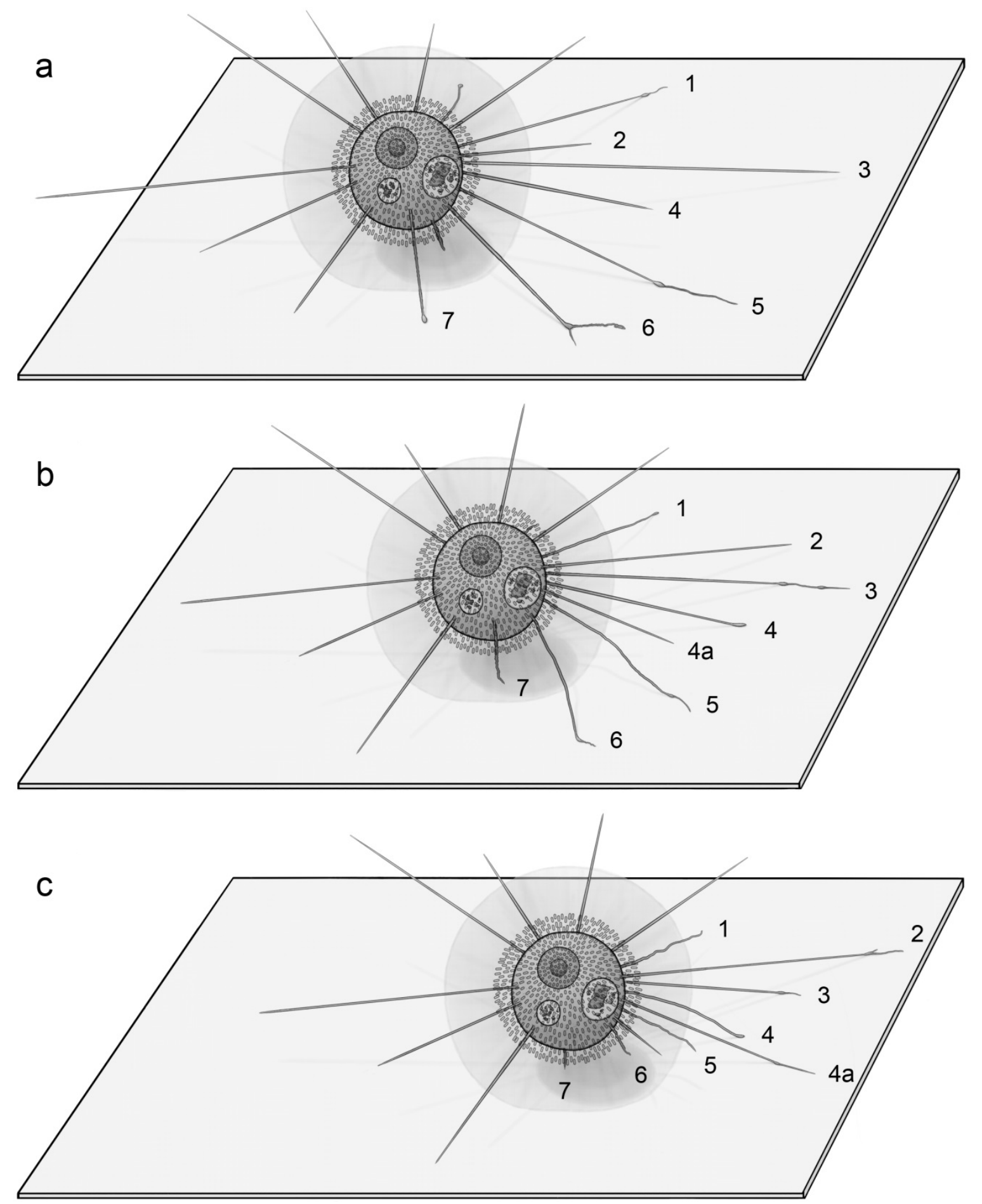

Figure 2 


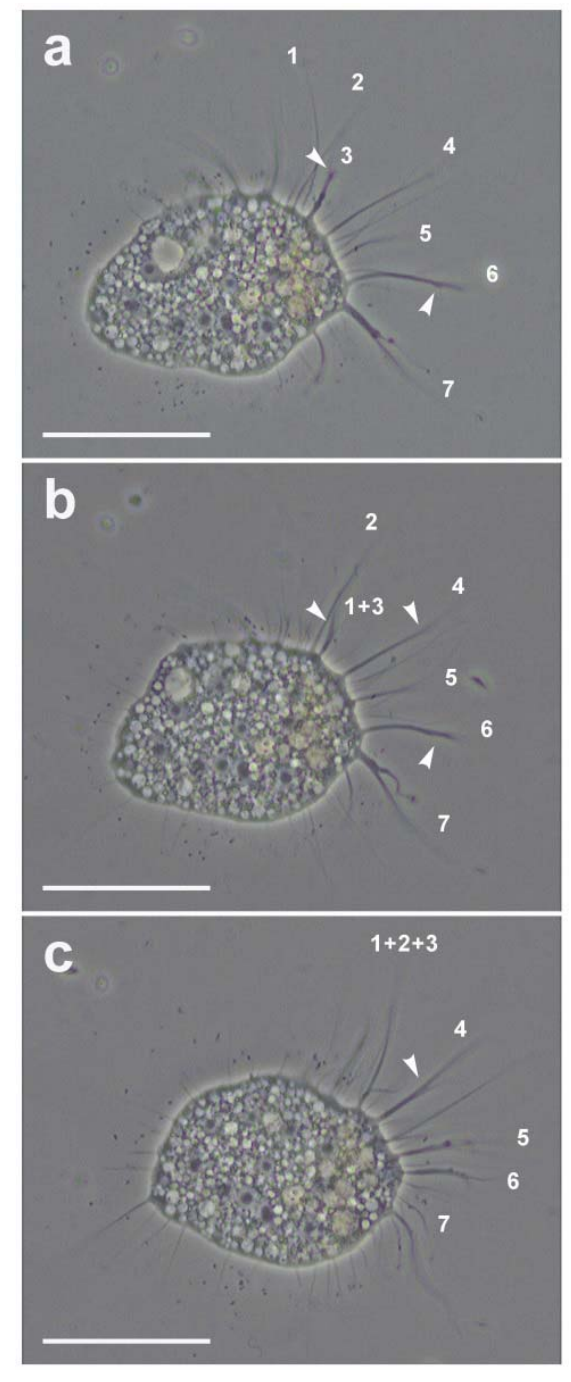

Figure 3
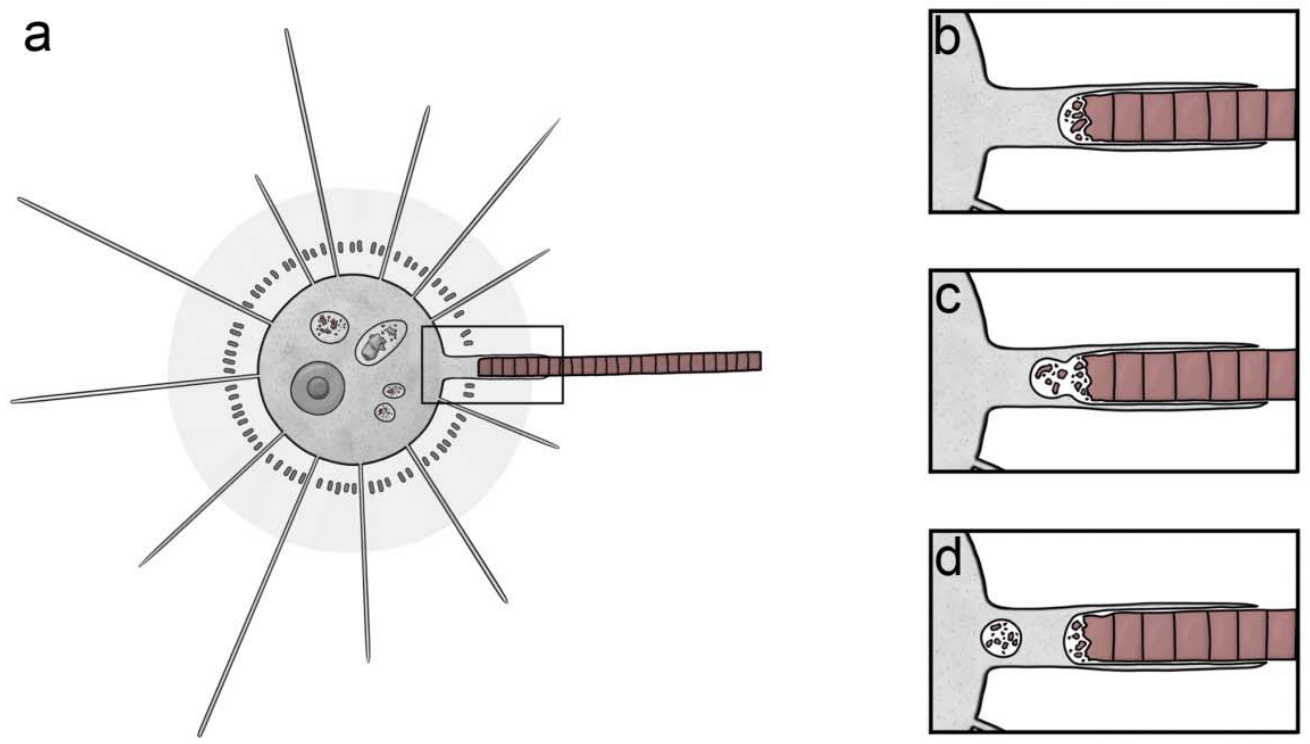

Figure 4 

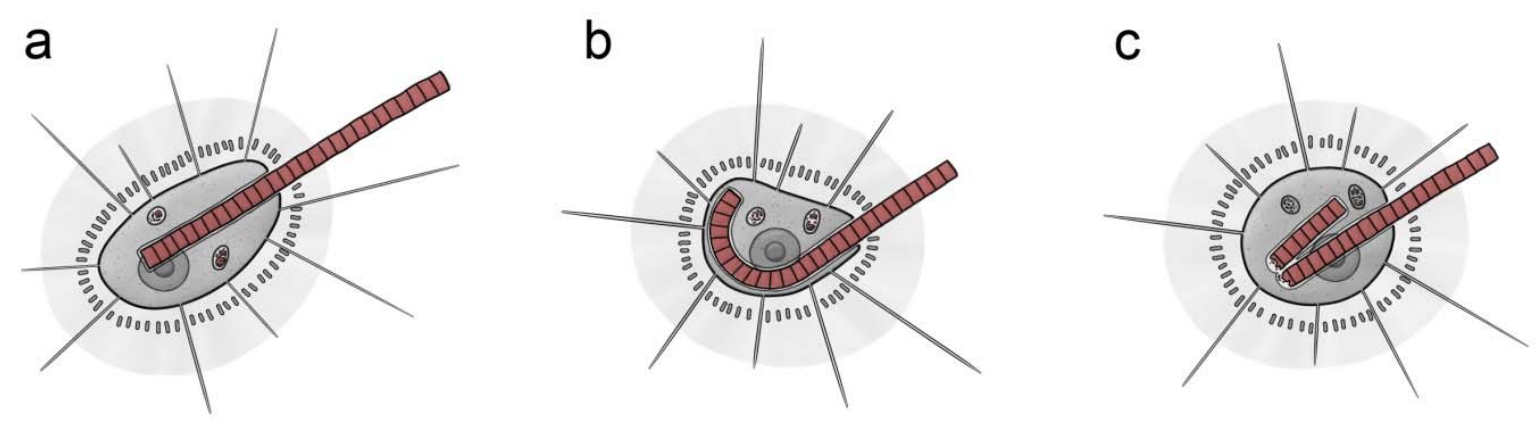

Figure 5

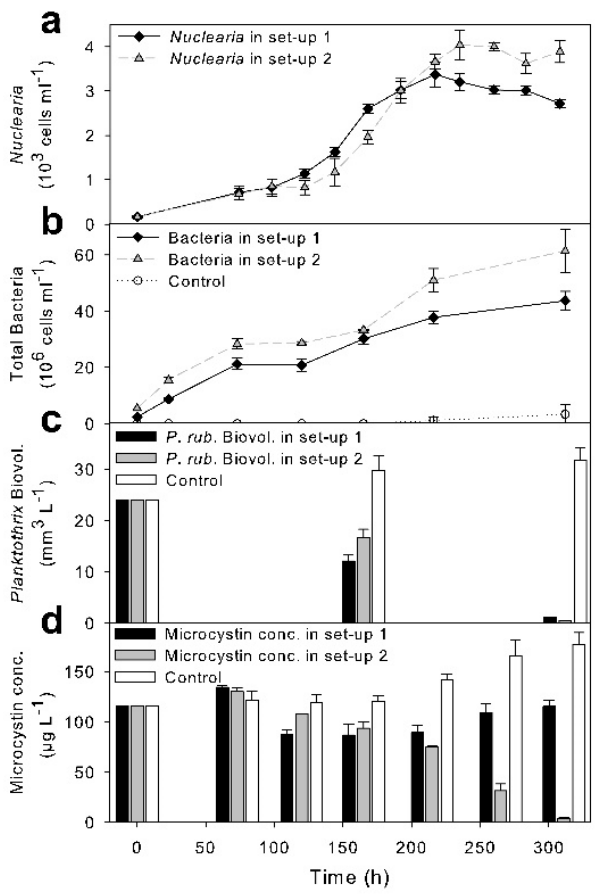

Figure 6

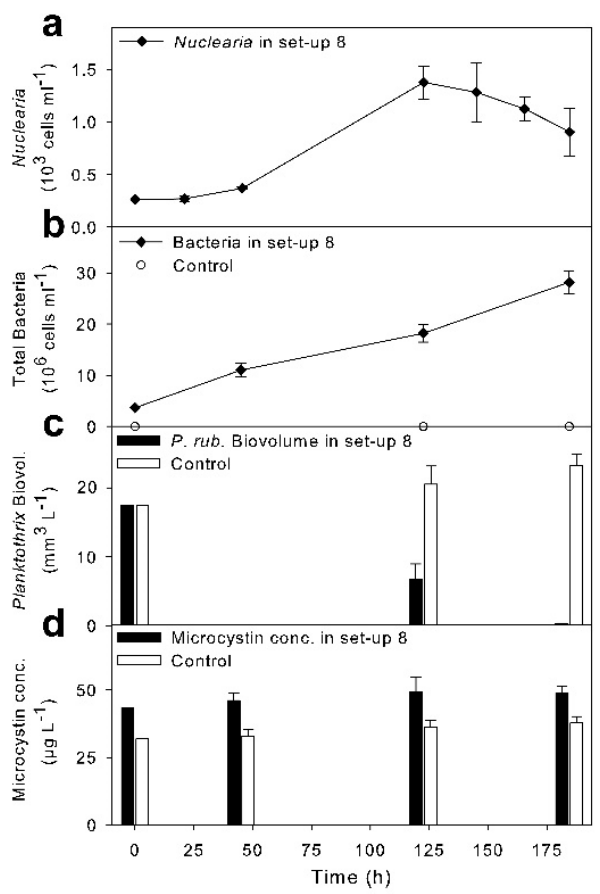

Figure 7 


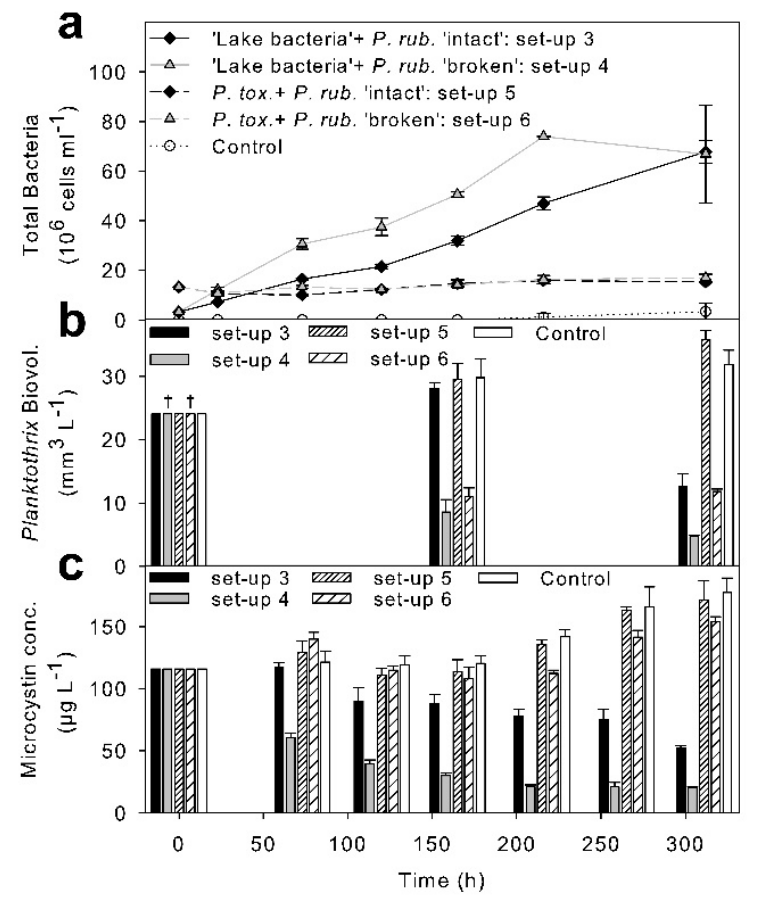

Figure 8 